\title{
LETTER TO THE EDITOR \\ CAN WEARING FACE MASKS IN PUBLIC AFFECT TRANSMISSION ROUTE AND VIRAL LOAD IN COVID-19?
}

\author{
Zuzana Stř̌žová, Jiřina Bartůñková, Daniel Smrž \\ Department of Immunology, Second Faculty of Medicine, Charles University and University Hospital Motol, Prague, Czech Republic
}

\section{SUMMARY}

The mandatory face mask wearing was implemented in the Czech Republic and Slovakia shortly after the COVID-19 outbreak in Central Europe. So far, the number of COVID-19-associated deaths per 100,000 individuals is far lower in these countries as compared with other neighbouring or close countries. The use of face masks in public may not protect the general public from contracting the virus, however, presumptively decreases the viral load and contributes to a favourable clinical outcome in COVID-19 disease. A certain time is required for antigen-specific T cells and B cells to fully develop. Obligatory face mask wearing in public favours the virus transmission through oral mucosa and/or conjunctival epithelium, which enables the adaptive immune responses to evolve. In the case of inhalation of high loads of SARS-CoV-2, the time for the development of fully protective adaptive immune responses seems to be insufficient. Then, a less specific and more damaging innate immune response prevails.

Key words: COVID-19, immunity, viral load, transmission route, COVID-19 face masks

Address for correspondence: Z. Strǐžová, Department of Immunology, Charles University, Second Faculty of Medicine and University Hospital Motol, V Úvalu 84, 15006 Prague 5, Czech Republic, E-mail: zuzana.strizova@fnmotol.cz

https://doi.org/10.21101/cejph.a6290

The COVID-19 pandemic caused by a rapid spread of virus SARS-CoV-2 has affected the population globally (1). In the Czech Republic, wearing face masks in public became obligatory on the 18th of March 2020 (2). Despite the lack of surgical masks and respirators in the coming few days, the Czech population have shown an enormous effort in the preparation and distribution of homemade face masks, which became soon after a part of every household (3). The World Health Organization (WHO) revealed on the 30th of March 2020 that there is no specific evidence suggesting that wearing face masks by the mass population is beneficial (4). Here we, however, discuss the low fatality rates in COVID-19 patients across the Czech population with the aim to highlight that the transmission route might indeed significantly affect the clinical course of the disease.

While in most European countries the pandemic precaution measures were the suspension of the city and suburban public transportation, the mandatory face mask wearing was implemented only in the Czech Republic and Slovakia shortly after the virus outbreak in Central Europe (2). The Czech Republic has 10,650,000 citizens, out of which almost 485,000 individuals were tested for COVID-19 infection by RT-PCR towards the beginning of June 2020 (5). The tests confirmed 9,700 positive cases and 7,000 cases of recovered patients. So far, there have been reported less than 340 COVID-19-associated deaths in this ten-million-population country (5). The proportion of infected individuals in other European countries does not significantly differ from the Czech Republic. However, the number of COVID19-associated deaths per 100,000 individuals is indeed far lower in the Czech Republic (3.09) as compared with other neighbouring or close countries, such as France (43.73), Italy (56.33), Spain (58.08), Switzerland (22.72), and Belgium (84.21) (6). Such low fatality rates are also seen in Slovakia (0.51) and South Korea $(0.53)$, where face mask wearing has also been required or at least advised $(2,6)$.

Understanding the factors which contribute to the severity and mortality of COVID-19 will require extensive research in the future. However, Chen et al. already suggested a relation between the viral load and the disease severity and raised an urge to investigate different factors affecting the viral load (7). Moreover, it has already been demonstrated that in the influenza pandemic, the use of personal protective measures, such as hand washing and face masks, reduced the risk of secondary influenza infection (8). The authors, Saunders et al., however, call for further evaluation of the relative impact of different routes of disease transmission (8).

During the COVID19 pandemic, the contribution of the faecaloral transmission route in the overall SARS-CoV-2 spreading was often debated (9). However, the differences in the fatality rates among the European countries could hardly be attributed to this route of spreading because hygiene standards and hygiene measures implemented by the governments of these countries after the pandemic outbreak were comparable. It is, therefore, unlikely that infected citizens of these European countries were exposed to 
different loads of the virus upon this route of transmission. Similar applies to virus transmission through conjunctival epithelium (10). So far, most of the COVID-19 patients are believed to be infected by contagious droplets and contact (1). The studies have not yet investigated whether inhalation of the virus-containing air after direct contact with COVID-19 positive individuals has a worse impact on the clinical outcome than the exposure to the infectious droplets through the oral mucosa. Regardless, the obligatory face mask wearing presumably plays a role in both these routes of the virus transmission.

The current epidemiological data already indicate that face mask wearing may reduce the emission of virus particles into the environment (11). The filtration efficacy has been studied across different materials to determine which face masks have superior potency to prevent the transmission of infectious droplets (12). The surgical mask had the highest filtration efficiency when challenged with viral aerosols and was, therefore, used as a control. Among common household materials, high efficacy in the prevention of virus transmission was observed in vacuum cleaner bags ( $86 \%$ filtration efficacy) and tea towels (73\% filtration efficacy). However, these materials are characterized by thickness and stiffness and may not be an optimal choice for a face mask. Linen has been shown to provide a filtration efficacy against infectious aerosols around $62 \%$, silk approximately $54 \%$, and cotton-mix approximately $70 \%$ (12). These results indicate that in the cases where the supply of surgical face masks is not available, homemade face masks may provide certain protection and reduce the inhaled viral load.

In healthy individuals wearing face masks, the transmission routes are either through limited physical contact with the face (i.e., a hand touch) or through inhalation of the decreased amount of the virus after the mask-mediated filtration of droplets and air (13). Therefore, the virus load each individual is exposed to in public may be lower. This lower virus load may not decrease the spread of the virus across the affected population but have presumably an impact on the quality of the immune response and the subsequent disease development in the infected individuals.

The crucial role of the innate and adaptive immune responses in COVID-19 has already been shown (14). However, a certain time is required for antigen-specific $\mathrm{T}$ cells and $\mathrm{B}$ cells to respond and fully develop to protect infected individuals against the virus through virus-neutralizing antibodies and cytotoxic CD8+ T cells that specifically recognize and eliminate the virus-infected cells (15). In the case of inhalation of high loads of SARS-CoV-2, the time for the development of fully protective adaptive immune responses seems to be insufficient. Then, a less specific and more damaging innate immune response prevails (14). The uncontrollable innate immune response often unleashes the cytokine storm and leads to the development of severe forms of the disease, or even death (14). To avert severe and deadly forms of the disease, the initial load of the virus needs to be decreased to gain more time for the specific and less damaging adaptive immune system to respond and develop efficient protection against the virus.

What can be learned from the obligatory face mask wearing in public? The countries, like the Czech Republic, where face mask wearing in public became obligatory at the beginning of the COVID-19 outbreak, show the lowest fatality rate. Even though face mask wearing may not protect the general public from contracting the virus, the use of both medical face masks and homemade face masks in public presumptively decreases the viral load (16). This may not slow down the spread of the virus, but it likely allows the immune system of the infected individuals to gain more time to respond and protect properly before the innate immunity-driven damaging form of the disease develops. This face-mask-given more time to the immune system might have been the crucial contributory momentum that had decided whether the COVID-19 pandemic turned deadly or not after its outbreak.

\section{Conflict of Interest}

None declared

\section{REFERENCES}

1. Han Y, Yang H. The transmission and diagnosis of 2019 novel coronavirus infection disease (COVID-19): A Chinese perspective. J Med Virol. 2020;92(6):639-44.

2. Cheng KK, Lam TH, Leung CC. Wearing face masks in the community during the COVID-19 pandemic: altruism and solidarity. Lancet. 2020 Apr 16;S0140-6736(20)30918-1. doi: 10.1016/S0140-6736(20)30918-1.

3. Tait R. Czechs get to work making masks after government decree The Guardian [Internet]. 2020 Mar 30 [cited 2020 March 30]. Available from: https://www.theguardian.com/world/2020/mar/30/czechs-get-to-workmaking-masks-after-government-decree-coronavirus.

4. Reuters. Lopatka J. Czech virus chief defends face masks order, says they protect others [Internet]. Reuters; 2020 Mar 31 [cited 2020 Jun 12]. Available from: https://www.reuters.com/article/health-coronavirusczech-masks/czech-virus-chief-defends-face-masks-order-says-theyprotect-others-idUSL8N2BO83P.

5. Ministry of Health of the Czech Republic. Up-to-date diseases. Covid-19: review of the present situation in the Czech Republic [Internet]. Prague: Ministry of Health of the Czech Republic [cited 2020 Apr 20]. Available from: https://onemocneni-aktualne.mzcr.cz/covid-19. (In Czech.)

6. John Hopkins University. Medicine. Coronavirus Resource Center. Maps $\&$ trends. Mortality analysis [Internet]. Baltimore: John Hopkins University; 2020 [cited 2020 Apr 25]. Available from: https://coronavirus.jhu. edu/data/mortality.

7. Chen Y, Li L. SARS-CoV-2: virus dynamics and host response. Lancet Infect Dis. 2020 May;20(5):515-6.

8. Saunders-Hastings P, Crispo JAG, Sikora L, Krewski D. Effectiveness of personal protective measures in reducing pandemic influenza transmission: A systematic review and meta-analysis. Epidemics. 2017 Sep;20:1-20.

9. Yuen KS, Ye ZW, Fung SY, Chan CP, Jin DY. SARS-CoV-2 and COVID-19: The most important research questions. Cell Biosci. 2020 Mar 16;10:40. doi: 10.1186/s13578-020-00404-4.

10. Lu CW, Liu XF, Jia ZF. 2019-nCoV transmission through the ocular surface must not be ignored. Lancet. 2020 Feb 22;395(10224):e39. doi: 10.1016/S0140-6736(20)30313-5.

11. Leung NHL, Chu DKW, Shiu EYC, Chan KH, McDevitt JJ, Hau BJP, et al. Respiratory virus shedding in exhaled breath and efficacy of face masks. Nat Med. 2020 May;26(5):676-80.

12. Davies A, Thompson KA, Giri K, Kafatos G, Walker J, Bennett A. Testing the efficacy of homemade masks: would they protect in an influenza pandemic? Disaster Med Public Health Prep. 2013 Aug;7(4):413-8.

13. Kutter JS, Spronken MI, Fraaij PL, Fouchier RA, Herfst S. Transmission routes of respiratory viruses among humans. Curr Opin Virol. 2018;28:142-51.

14. Shi Y, Wang Y, Shao C, Huang J, Gan J, Huang X, et al. COVID-19 infection: the perspectives on immune responses. Cell Death Differ. 2020;27(5):1451-4.

15. Zheng M, Gao Y, Wang G, Song G, Liu S, Sun D, et al. Functional exhaustion of antiviral lymphocytes in COVID-19 patients. Cell Mol Immunol. 2020 May; 17(5):533-5.

16. Ma QX, Shan H, Zhang HL, Li GM, Yang RM, Chen JM. Potential utilities of mask-wearing and instant hand hygiene for fighting SARS-CoV-2. J Med Virol. 2020 Mar 31:10.1002/jmv.25805. doi: 10.1002/jmv.25805. 